Jurnal Teknologi, 34(C) Jun 2001: 9-16

(C) Universiti Teknologi Malaysia

\title{
THE DEVELOPMENT OF FLUXGATE MAGNETOMETER FOR NON-DESTRUCTIVE MEASUREMENT
}

\author{
CHEW SOON LEONG ${ }^{1}$, RASHDI SHAH AHMAD ${ }^{2} \&$ ROSLY JAAFAR ${ }^{3}$
}

\begin{abstract}
Non-Destructive measurements of ferromagnetic material and low frequency magnetic flux disturbance require a highly sensitive and stable magnetic sensor with directional capabilities. A magnetometer based on fluxgate principle that meets the requirement had been developed using a ferrite ring core. The ferrite ring core is excited by an excitation current source to achieve hysteresis condition. The pick up coil that is wound across the ring core will pick up the magnetic flux generated in the ring core. This sensing method is based on the conventional type of fluxgate magnetometer with detection of second harmonics by a phase sensitive detector. Major advantages of the fluxgate magnetometer are low cost, directional, easy to construct, reliable and rugged.

Key words: Fluxgate, magnetic sensor, hysteresis, ferromagnetic

Abstrak: Pengukuran tanpa musnah bahan feromagnet dan gangguan medan magnet frekuensi rendah memerlukan penderia medan magnet yang mempunyai kepekaan yang tinggi dan stabil. Magnetometer yang berasaskan prinsip fluxgate dan memenuhi ciri-ciri yang diperlukan telah dibina dengan menggunakan teras gelang ferit. Teras gelang ferit ini dipacukan dengan sumber arus untuk mencapai keadaan histerisis. Gelung pengesan yang dililit merentasi gelang ferit akan mengesan perubahan medan magnet yang berlaku pada gelang ferit tersebut. Teknik pengesanan yang digunakan adalah berasaskan pengesanan harmonik kedua oleh suatu pengesan fasa. Penderia fluxgate yang dibina adalah murah, mudah dibina, mampu mengesan arah medan magnet dan tahan lasak.
\end{abstract}

Kata kunci: Fluxgate, penderia medan magnet, histerisis, feromagnet

\subsection{INTRODUCTION}

Fluxgate magnetometer that was first introduced in 1930's is a solid-state device for measuring the magnitude and direction of the D.C. or low frequency A.C magnetic field in the range $10^{-10}$ to $10^{-4} \mathrm{~T}$. They are reliable, rugged as they contain no moving parts, very low energy consumption and can reach $10 \mathrm{pT}$ resolution and 1 nT long-term stability. Fluxgate has advantages over other types of field sensors in certain area of field intensities and frequency measurements. It is about five orders of magnitude more sensitive than other solid-state devices like magneto-resistors and

$1,2 \& 3 \quad$ NDT Research \& Services Group, Jabatan Fizik, Fakulti Sains, Universiti Teknologi Malaysia, 81310 Skudai, Johor Darul Takzim, Malaysia. Tel: 07-5576160 ext. 4250/4088, Fax: 07-5566162, e-mail: shah@dfiz2.fs.utm.my. 
Hall effect sensors. Unlike the induction magnetometers, which register field changes only, fluxgate sensors may be used for absolute measurements besides measuring the direction of the field. Fluxgate sensors are much cheaper than the more sensitive magnetic sensor SQUIDS and need no liquid helium for operation [1].

The main fields of application of fluxgate sensors are: geophysical measurements; space research; identification, location and compasses; measurements of electric current and non-destructive measurements [1].

The purpose of this project is to construct an inexpensive magnetometer for nondestructive measurement.

\subsection{THEORY OF OPERATIONS}

The magnetic field fluxgate sensor consists of a ferromagnetic core with a primary excitation winding and a secondary pick-up coil (see Figure 1).

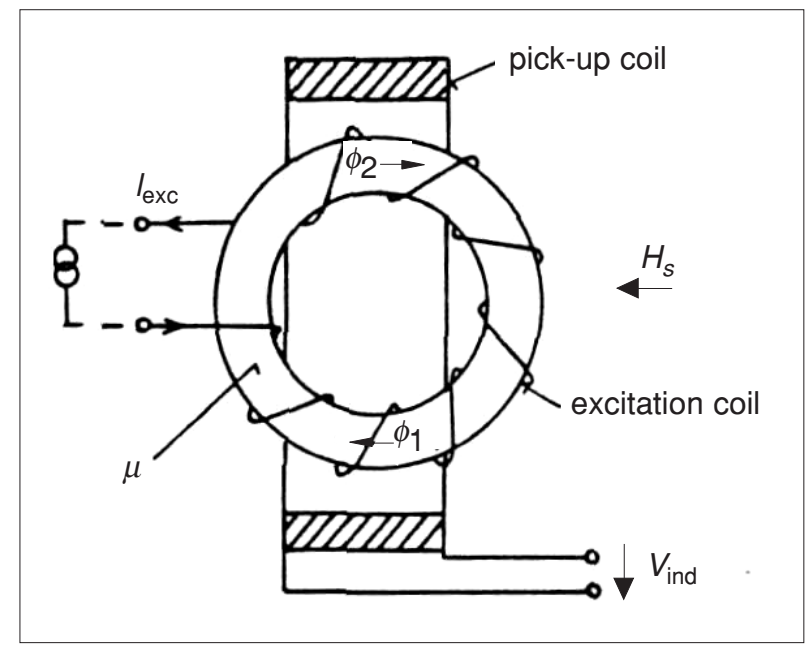

Figure 1 The simple fluxgate sensor [1]

The core is periodically driven into saturation by a suitably large alternating excitation current, whereby the core differential permeability $\left(\mu_{d}\right)$ becomes zero twice for a period of excitation. In the ideal case, the core and the secondary coil geometry are open to external magnetic fields, whereas the primary excitation magnetic circuit is intended to be closed and decoupled as far as possible to the secondary coil to reduce the offset and noise of the fluxgate sensor.

An alternating voltage consists of second and higher even harmonics is induced in the secondary coil by the combination of external magnetic field and the periodically changing core permeability. In the actual case, the alternating voltage consists of odd and second higher order harmonics. The odd harmonics, which can be considered as noise detected by the secondary coil, is the result of decoupling effect 
by "residual transformer" phenomena, which is also called mutual inductance effect.

D. I. Gordon and R. E Brown [2] had derived an expression for the even harmonic portion of the output or secondary coil voltage $E_{o}$, based on Faraday's induction law and utilizing ferromagnetic core material parameters, and the expression is

$$
E_{o}=E_{p}\left(\frac{N}{N_{p}}\right)^{2} \mu_{a} \frac{\mu_{d}^{\prime}}{\mu_{d}^{2}} H_{s}
$$

$E_{0}=$ even harmonic portion of the output (secondary coil) voltage.

$E_{p}=$ driving (primary excitation) voltage

$N=$ Number of output (secondary coil) winding.

$N_{p}=$ Number of primary winding.

$H_{s}=$ signal field

$m_{d}=\frac{d B}{d H}$, differential permeability

$\mu_{d}^{\prime}=\frac{d^{2} B}{d H^{2}}$

$\mu_{\mathrm{a}}=$ apparent permeability of the core to the signal field $H_{s}, \mu_{d} /\left(1+K \mu_{d}\right)$, where $K$ is the demagnetization factor of the core.

Based on Eq. 1, the magnetic properties of the ferromagnetic core such as differential permeability, coercive force and demagnetizing factor will contribute to the sensitivity of the sensor. Ferrite, a composite material with high permeability, high resistivity, high Curie temperature and low coercive force had been chosen as the core for the fluxgate sensor. This is because the high resistivity of ferrite will decrease the eddy current losses when it is driven with high frequency alternating current. According to P. Ripka [1] ring core geometry fluxgate sensors have lower signal to noise ratio compared with open-end geometry fluxgate sensors.

\subsection{METHODOLOGY}

\subsection{Sensor Construction}

The ring core used in the fluxgate sensor was taken from a ferrite sleeve that was used to made inductor or high frequency EMI (Electromagnetic Interference) filter. It is easy to get and cheap.

The original size of ferrite sleeve is not suitable for the core of fluxgate sensor so the ferrite sleeve was ground and polished to the required size by using sand papers. The size of the final ferrite ring core is about $16 \mathrm{~mm}$ OD (outer diameter), $12 \mathrm{~mm}$ ID 
(internal diameter) and $2 \mathrm{~mm}$ thick. The ferrite ring was wound with 168 turns of $0.2 \mathrm{~mm}$ diameter enameled copper wire. As windings progress, the turns were kept closely wound on the internal diameter and evenly on the outer diameter.

The completed ferrite ring with primary coil was put in a secondary coil housing, which was specially constructed to hold the pick up coil. The secondary winding or the pick up coil has 670 turns of $0.12 \mathrm{~mm}$ diameter enameled copper wire.

\subsection{Magnetometer Electronics}

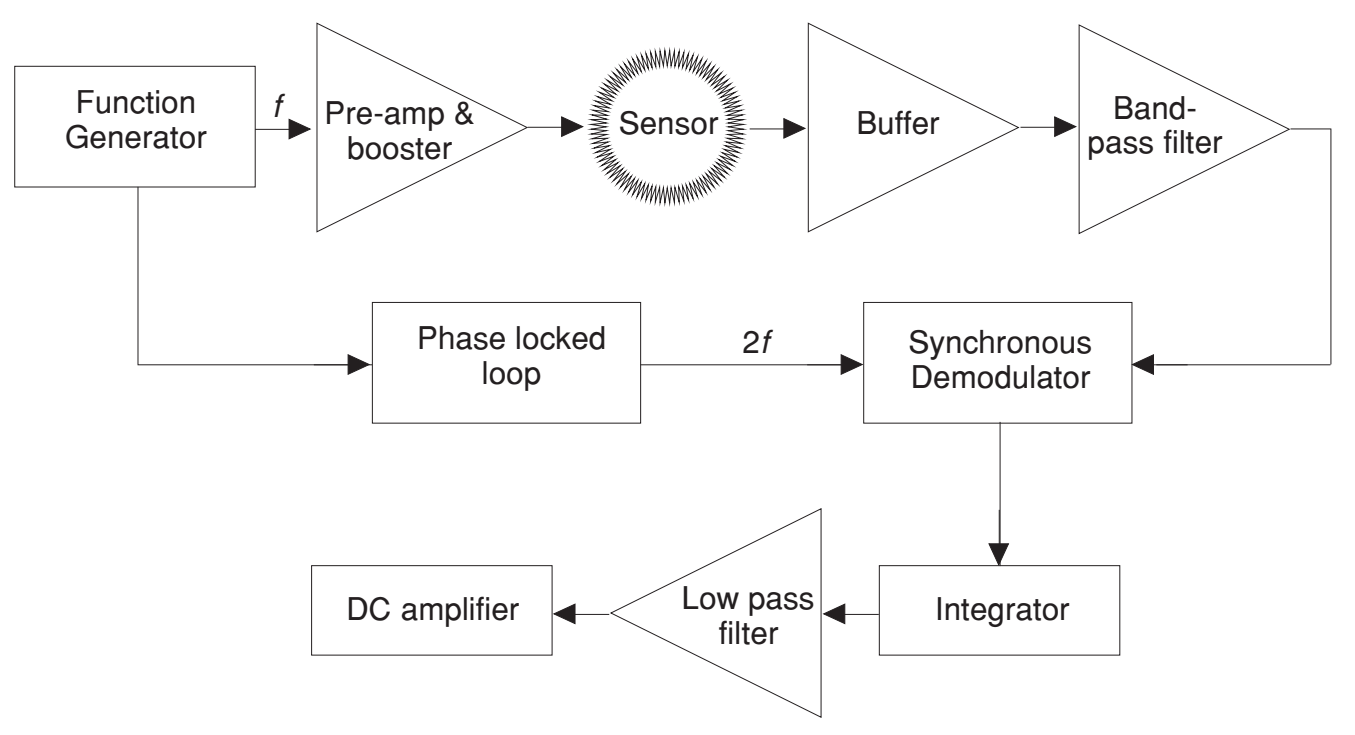

Figure 2 Block diagram of fluxgate magnetometer

The block diagram of the magnetometer is shown in Figure 2. It consists of a function generator, pre-amplifier and current booster, fluxgate sensor, buffer or voltage follower, band-pass filter, phase locked loop, synchronous demodulator, low pass filter and DC amplifier. The phase locked loop, synchronous demodulator and integrator build up a system known as phase sensitive detector (PSD).

In order to magnetically saturate the ferrite core, an alternating triangular current had been applied to generate adequate magneto-motive force $(\mathrm{mmf})$ for driving the sensor. A triangular signal of frequency $f$ generated by the function generator (ICL8038) is amplified by a low-noise and low second harmonic distortion preamplifier (AD595) to drive the sensor. The function of the IC (AD595) is to reduce the offset voltage generated in the pickup coil. This is because the second harmonic content in the driving wave, which is in phase with the reference wave, may be fed through the pickup coil via residual transformer action to generate false signal in the sensor [3]. The function generator also produces a square wave signal of frequency 
$f$ to be used as reference signal for the phase sensitive detector (PSD). The triangular signal is boosted by using Class $\mathrm{AB}$ push-pull complementary amplifier that has low second harmonic distortion.

The sensor drive circuit is a lossy inductor whose inductance is a nonlinear function of the drive current. A simple solution is to tune the drive winding to the drive frequency by a series capacitors [3]. This matching method has several advantages. First, the capacitor blocks any DC in the drive wave if there is a possible offset in the drive amplifier. This is important because DC in the drive signal will generate second harmonic signal that gives offset to the sensor. Second, on average, the tuning will balance the sensor drive inductance making the load more resistive. This can improve the power transfer factor of the drive circuit and sensor. Finally, the nonlinear characteristic of the drive inductance will result in the "parametric resonance" [3]. The secondary coil inductance is a non-linear function of the permeability of the ferrite core. A buffer with high input impedance and ultra low noise configurations constructed using an ultra-low noise op-amp (LT 1028) has been added to strengthen the output signal. The buffer output is filtered using an IGMF (infinite-gain multiplefeedback) band-pass filter operating at $2 f$ resonance frequency to eliminate the odd and higher even harmonics signals detected by the secondary coil.

As the synchronous demodulator is phase sensitive, it is therefore called a phase-sensitive detector (PSD). Since the output of the fluxgate sensor is amplitude modulated by the measured field, the function of PSD is to demodulate the output signal back to DC or near zero frequency. The reference square wave signal of twice the excitation frequency $2 f$, with very short transient is provided by the phase lock loop IC (CD4046). To remove higher frequency as the result of the multiplication process in the PSD, a low pass filter at the output of the PSD is necessary.

\subsection{Calibration System}

Since the output of the fluxgate magnetometer is a DC or low frequency voltage, calibration of the fluxgate sensor is needed to determine the conversion factor of the DC output voltage with the external magnetic field $H_{s}$. A simple calibration block using a pair of Helmholtz coil had been setup, as shown in Figure 3. Helmholtz coil was introduced for calibrating the fluxgate magnetometer because it can generates very uniform magnetic field up to $30 \%$ covered area from the centre axis if powered by a constant current source.

The magnetic field, $H_{s}$ generated by the Helmholtz coil was monitored using a calibrated 3 axis fluxgate magnetometer Model 520A from Applied Physics Systems. The calibration was done within the range $-30 \mu \mathrm{T}$ to $+30 \mu \mathrm{T}$ by adjusting the constant current supply. Output of the fluxgate sensor, in volt was plotted against the magnetic field detected by the calibrated magnetometer. 


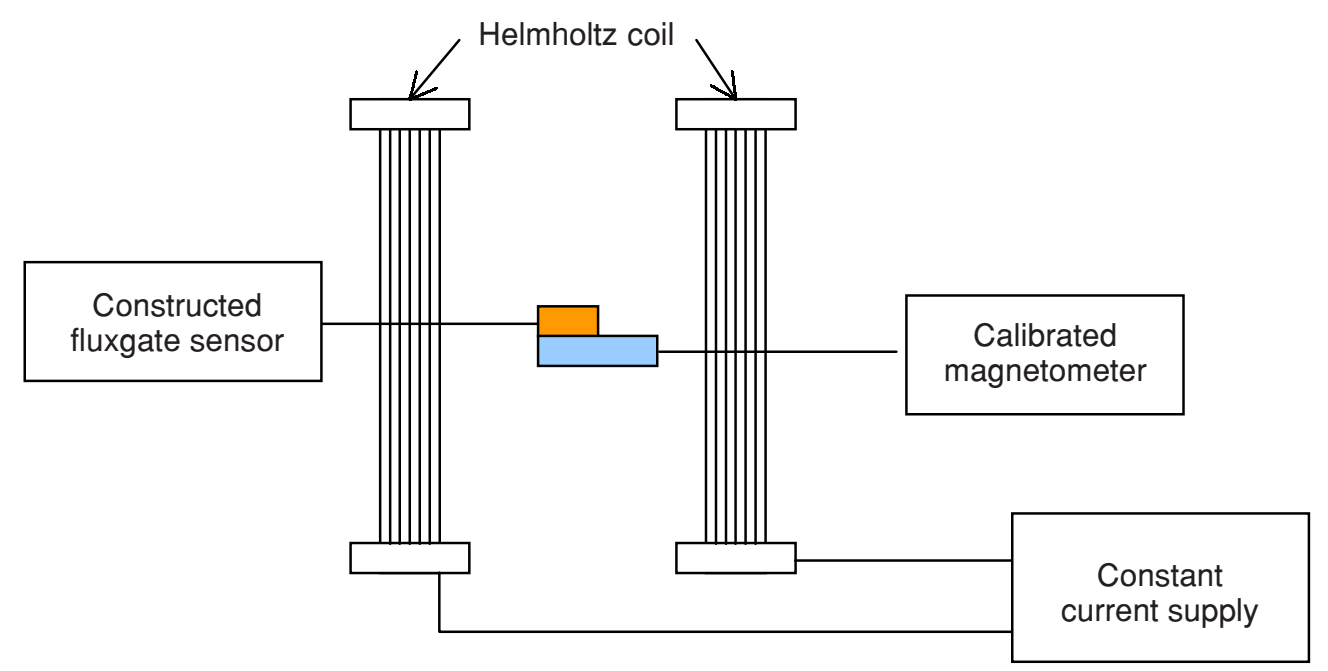

Figure 3 Simple magnetometer calibration system

\subsection{RESULTS AND DISCUSSION}

The result of the calibration is shown in figure 4 . The figure shows that the output of the fluxgate sensor is linear in the range of $-30 \mu \mathrm{T}$ to $+30 \mu \mathrm{T}$. The minimum strength of magnetic field $H_{s}$, which can be detected by the sensor, is about $330 \mathrm{nT}$. The detection limit is determined by the smallest yet stable D.C voltage that can be obtained from the magnetometer. The output voltage is linear to magnetic field

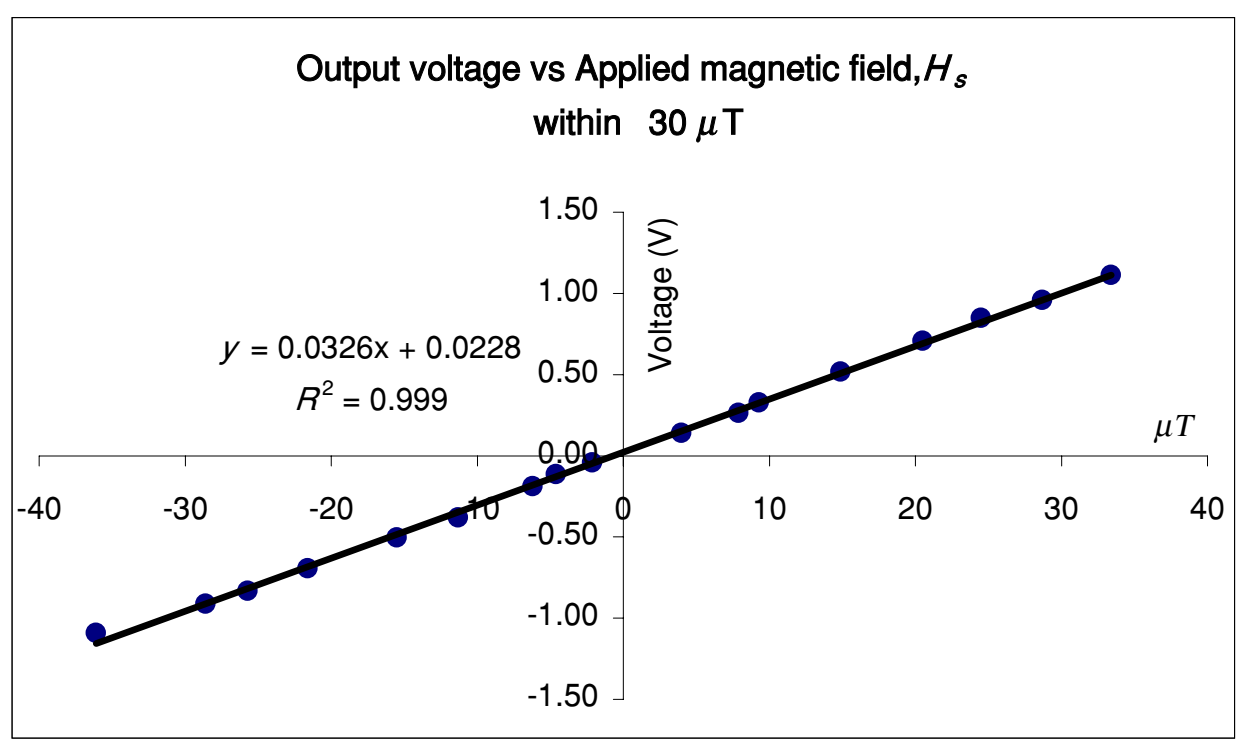

Figure 4 Output voltage for different applied magnetic field 
strength with regression coefficient of 0.999 . The sensitivity of the sensor, which is determined from the slope of the line, is $33 \mathrm{mV} / \mu \mathrm{T} \pm 0.8 \%$.

\subsection{CONCLUSION}

A single axis fluxgate magnetometer for non-destructive testing application was successfully constructed. The response is linear from $-30 \mu \mathrm{T}$ to $+30 \mu \mathrm{T}$. It can measure the strength of magnetic field as low as $300 \mathrm{nT}$.

With these characteristics, the fluxgate magnetometer is able to detect the magnetic flux leakage produced by a fractured steel rod without applying external magnetic source to the subject. In addition, the fluxgate magnetometer can also be used to locate undercover or buried ferromagnetic material like steel rod in concrete structure.

To increase the detection capability of the detector so that a smaller change in magnetic field strength (less than $300 \mathrm{nT}$ ) can be measured, the resolution of the sensor needs to be improved.

\subsection{ACKNOWLEDGEMENT}

The authors wish to thank IRPA Grant (Grant No. 72218), Mr. Jose M.G. Merayo from The Technical University of Denmark for providing his knowledge and their collection of literatures. The first author, Chew, S. L, is a post-graduate student majoring in Physics Industry of Universiti Teknologi Malaysia. The second author, Ahmad, R.S, Ph. D in BioMedical Engineering of Hokkaido University, is a lecturer and researcher specializing in sensor and system development. He is also the supervisor to the first author. Dr. Rosly is one of the researchers in the Non-Destructive Testing (NDT) group at UTM.

\section{REFERENCES}

[1] P. Ripka (1992). Review of fluxgate sensor. Sensors and actuators. A 33: 129 - 141.

[2] D. I Gordon and R. E Brown (1972). Recent Advances in Fluxgate Magnetometry. IEEE Transactions on Magnetics. Mag-8: $76-82$.

[3] F. Primdahl (1979). The fluxgate magnetometer. J. Phys. E: Sci. Instrum. 12: 241 - 253. 